\title{
Evaluation of the Health Education and Literacy Program (HELP) to Community Residents
}

\author{
Mauro Allan P. Amparado * \\ Rose Delia P. Ocariza ** \\ University of Cebu Lapu-Lapu and Mandaue, \\ Mandaue City, Cebu, Philippines \\ mapamparado@gmail.com \\ rdocariza@yahoo.com
}

* Director, Community Awareness Relations \& Extension Services, UCLM

${ }^{* *}$ Clinical Instructor, College of Nursing, UCLM

\section{Abstract}

The study evaluated the impact of the health education and literacy program (HELP) to community beneficiaries. Findings served as bases for an enhanced annual plan for 2019 to 2020.

This descriptive study was conducted in Village Looc and Village Opao, Mandaue City, Cebu, Philippines to evaluate the health education and literacy program (HELP) to its beneficiaries which was implemented from June 2018 to May 2019. A total of 85 mothers were surveyed utilizing a researcher-made questionnaire. The questionnaire was composed of a profile section and an evaluation of health topics which were provided as lectures to community residents.

The respondents were satisfied with the twelve health education topics taught to them for the entire year. Among the twelve topics, the top six topics with the highest means were 
prostate cancer, breast cancer, skin diseases, dengue fever, Diabetes Mellitus, and Asthma.

Residents were also satisfied with the other six health education topics. These were smoking-related diseases, HIV/AIDS, oral hygiene, Tuberculosis, stress, and conjunctivitis. Although the residents were satisfied, there is still room for improvement.

Based on the findings of the study, the residents were satisfied with the health education and literacy program. However, there is a need to re-teach the concepts and institute strategies that will facilitate the residents to reach high satisfaction on the program.

Keywords: Satisfaction; Impact; Health Education; Literacy; Mandaue City, Cebu, Philippines

\section{Introduction}

Today, patient education is a topic of significant interest to nurses in every setting in which they practice. Teaching is a major aspect of the nurse's professional role. The current trends in health care are making it essential that patients and their families are prepared to assume responsibility for selfcare management. The focus of care is on outcomes that demonstrate the extent to which patients and their significant others have learned the knowledge and skills necessary for independent living. The need for nurses to teach others and to help others learn will continue to increase in this era of healthcare reform. With changes rapidly occurring in the system of healthcare delivery, nurses will find themselves in increasingly demanding, constantly fluctuating and highly complex positions. Nurses in the role of teachers must understand the forces, both historical and present day, that 
have influenced and continue to influence their responsibilities in practice (Bastable, 2006).

The educator role of the home health nurse focuses on teaching illness care, the prevention of problems, and the prevention of optimal wellness or well-being to the client, the family, and other related persons. A common example is that of guiding the health and development of newborns. Some clients of all ages have acute illness that will resolve, while others have chronic conditions that will last a lifetime. The nurse's teaching and learning methods will vary based on the need of these clients. The nurse may also be involved in teaching others with whom the client interacts such as school teachers of special-needs children. Education is ongoing can be considered the crux of home care practice; its goal is to help clients learn to manage as independently as possible. All home health nurses need to be skilled in teaching and learning principles and strategies that facilitate learning (Berman, et al, 2008).

Health Education is the participatory educational approach, often used interchangeably with the term patient education or client education, aimed at preventing disease, promoting health, and incorporating the physical, mental, and social aspects of learning needs (Bastable, 2006).

According to the Alma Ata Declaration, Primary Health Care "is essential health care based on practical, scientifically sound, and socially acceptable methods and technology. Made universally accessible to individuals and families in the community through their full participation and at a cost that the community and country can afford to maintain at every stage of their development in the spirit of self-reliance and self-determination." Through the years, Primary Health Care has made a significant impact in terms of changing the 
process of governance in health. This can be seen in the need to motivate volunteer workers to participate in community health management, the recognition of alternative technologies to manage ailments, fostering intersectoral partnerships, enabling the interface of non-government organizations in governance and the mobilization of people's organizations to take part in addressing their health and other needs. More importantly, subscribing to a participatory ethic has helped in improving quality of life (Bautista, 2001).

A recent study described the health promotion activities of community health nurses working in the South Western Sydney Area Health Service. This was part of an evaluation of the Health for All policy on health promotion activities of community health nurses. Using focus group discussion as the methodology for gathering data, the nurses described their health promotion activities as health education targeted to individuals and families. Health education was perceived as the transfer of information, the provision of emotional and social support, and networking and empowerment of the client. The study also revealed that the nurses' interpretation of health promotion was limited, as manifested by activities such as promoting immunizations and improved family nutrition through Mother's Advisory Services; prevention of injuries among the young and the elderly; skin cancer prevention and related interventions promoted by the government (Palaganas, 2005).

Anchored on the Health Promotion Model (HPM) by Nola Pender, the model is an attempt to depict the multifaceted nature of persons interacting with the environment as they pursue health. Unlike avoidanceoriented models that rely upon fear or threat to health as motivation for health behavior, the HPM has a competence or approach-oriented focus. Health promotion is motivated by 
the desire to increase well-being and actualize human potential (Tomey \& Aligood, 2002).

There are 14 theoretical assertions derived from the model. This includes the following: (1) Prior behavior and inherited and acquired characteristics influence beliefs, affect, and enactment of health-promoting behavior; (2) Persons commit to engaging in behaviors from which they anticipate deriving personally valued benefits; (3) Perceived barriers can constrain commitment to action, mediator of behavior, and actual behavior; (4) Perceived competence or self-efficacy to execute a given behavior increases the likelihood of commitment to action and actual performance of behavior; (5) Greater perceived self-efficacy results in fewer perceived barriers to specific behavior; (6) Positive affect toward a behavior results in greater perceived self-efficacy, which can, in turn, result in increased positive affect; (7) When positive emotions or affect are associated with a behavior, the probability of commitment and action are increased (Tomey \& Aligood, 2002).

Furthermore, the models asserts that: (8) Persons are more likely to commit to and engage in health-promoting behaviors when significant others model the behavior, expect the behavior to occur, and provide assistance and support to enable the behavior; (9) Families, peers, and healthcare providers are important sources of interpersonal influence that can increase or decrease commitment to and engagement in health-promoting behavior; (10) Situational influences in the external environment can increase or decrease commitment to or participation in health-promoting behavior; (11) The greater the commitment to a specific plan of action, the more likely health-promoting behaviors are to be maintained over time; (12) Commitment to a plan of action is less likely to result in the desired behavior when competing 
demands over which persons have little control require immediate attention; (13) Commitment to a plan of action is less likely to result in the desired behavior when other actions are more attractive and thus preferred over the target behavior; (14) Persons can modify cognitions, affect, and the interpersonal and physical environments to create incentives for health action (Tomey \& Aligood, 2002).

One of the institutional goals of the University of Cebu Lapu-Lapu and Mandaue (UCLM) is to develop social awareness, responsibility and accountability among stakeholders anchored on instruction, research and production (Amparado, 2013). In 2008, UCLM partnered with Village Looc, Mandaue City, Cebu, Philippines and identified its community needs through a research grant funded by the university. The researchers discovered that the residents' needs were solid waste management, livelihood and literacy programs (Amparado, Camayra, Dorio Jr. \& Patindol, 2017).

The university also assessed the community needs of Village Opao, Mandaue City, Cebu, Philippines. Researchers revealed that the sustainable programs of the university for the village shall include literacy, livelihood, backyard gardening, livestock raising, flooding, family planning, administration of tetanus toxoid, and community participation programs (Amparado \& Colonia, 2020).

In the third study funded by the university, assessed the health education and literacy needs of two partner communities. The study reveals that the residents' top ten needs are prostate cancer, breast cancer, smoking-related diseases, stress, diabetes mellitus, asthma, dengue, tuberculosis, HIV/AIDS, skin diseases and oral hygiene (Amparado \& Ocariza, 2018). 
The College of Nursing has implemented the Health Education and Literacy Program (HELP) for SY 2019-2020. Evaluating the impact of the program will help the College of Nursing to improve the delivery of instruction and create changes in the program that will benefit the residents of Village Looc and Village Opao, Mandaue City, Cebu, Philippines.

\section{Objectives}

The study evaluated the impact of the health education and literacy program (HELP) to community beneficiaries. Findings served as bases for an enhanced annual plan for 2019 to 2020.

\section{Methods}

This descriptive study was conducted in Village Looc and Village Opao, Mandaue City, Cebu, Philippines to evaluate the health education and literacy program (HELP) to its beneficiaries which was implemented from June 2018 to May 2019. A total of 85 mothers were surveyed utilizing a researcher-made questionnaire. The respondents were residents of Village Looc and Village Opao, both villages located in Mandaue City, Cebu. The questionnaire was composed of a profile section and an evaluation of health topics which were provided as lectures to community residents.

To interpret the data, simple percentage and weighted mean was used. For the interpretation, the following ranges were utilized: 
$\begin{array}{ll}1.75-2.49 & \text { Less satisfied } \\ 1.00-1.74 & \text { Not satisfied }\end{array}$

\section{Results and Discussion}

This section presents the findings of the study. The table shows that the respondents were satisfied (2.83) with the twelve health education topics taught to them for the entire year. Among the twelve topics, the top six topics with the highest means were Prostate cancer (3.07), Breast cancer (3.08), skin diseases (3.00), Dengue fever (2.93), Diabetes Mellitus (2.86), and Asthma (2.78).

Residents were also satisfied with the other six health education topics. These were smoking-related diseases (2.76), HIV/AIDS (2.76), oral hygiene (2.76), Tuberculosis (2.69), stress (2.66), and conjunctivitis (2.64). Although the residents were satisfied, there is still room for improvement.

This implies that there is a need to re-teach the health education topics to the residents. The twelve topics shall form part of the annual plan of SY 2019-2020.

Table 1. Satisfaction of Respondents on HELP

\begin{tabular}{|l|c|c|c|}
\hline Topics & Mean & Interpretation & Rank \\
\hline $\begin{array}{l}\text { Prostate } \\
\text { Cancer }\end{array}$ & 3.07 & Satisfied & 1 \\
\hline Breast Cancer & 3.08 & Satisfied & 2 \\
\hline $\begin{array}{l}\text { Smoking- } \\
\text { related } \\
\text { diseases }\end{array}$ & 2.76 & Satisfied & 8 \\
\hline Stress & 2.66 & Satisfied & 11 \\
\hline
\end{tabular}




\begin{tabular}{|l|c|c|c|}
\hline $\begin{array}{l}\text { Diabetes } \\
\text { Mellitus }\end{array}$ & 2.86 & Satisfied & 5 \\
\hline Asthma & 2.78 & Satisfied & 6 \\
\hline Dengue Fever & 2.93 & Satisfied & 4 \\
\hline Tuberculosis & 2.69 & Satisfied & 10 \\
\hline HIV/AIDS & 2.76 & Satisfied & 8 \\
\hline Skin Diseases & 3.00 & Satisfied & 3 \\
\hline Oral Hygiene & 2.76 & Satisfied & 8 \\
\hline Conjunctivitis & 2.64 & Satisfied & 12 \\
\hline Grand Mean & 2.83 & Satisfied \\
\hline
\end{tabular}

\section{Conclusion}

Based on the findings of the study, the residents were satisfied with the health education and literacy program. However, there is a need to re-teach the concepts and institute strategies that will facilitate the residents to reach high satisfaction on the program.

\section{Literature Cited}

Amparado, M. A. P. (2013). University of Cebu Research Center Manual. Philippines: University of Cebu.

Amparado, M. A. P., Camayra, M. T., Dorio Jr., P. A. \&

Patindol, D. B. (2017). Sustainable Community Extension Programs for Village Looc, Mandaue City, Cebu, Philippines: The $8^{\text {th }}$ year Re-assessment. IAMURE International Journal of Social Sciences, 19(1), 102-114.

Amparado, M. A. P. \& Colonia, G. E. (2020). Community Needs Assessment of Village Opao, Mandaue City, Cebu, Philippines. Cebu Journal of Teacher Education, 
1(1), 83-100.

Amparado, M.A.P. \& Ocariza, R.D.P. (2018). Assessing the health education and literacy needs of partner communities. Philippines: University of Cebu LapuLapu and Mandaue. Cebu Journal of Nursing, 1(1), 2540.

Bastable, S. (2006). Essentials of patient education. USA: Jones and Barlett Publishers.

Bautista, V. A. (2001). Challenges to Sustaining Primary Health Care in the Philippines. Public Policy, 5(2), 89.

Berman, A. et al. (2008). Fundamentals of nursing concepts, process and practice. Singapore: Pearson Education South Asia Pte Ltd.

Famorca, Z. et al. (2013). Nursing care of the community. Malaysia: Elsevier.

Palaganas, E. (2005). Health care practice in the community. Philippines: Guiani Publishing.

Potter, PA \& Perry AG. (2005). Fundamentals of nursing practice. Singapore: Elsevier.

Tan, Cristita. (2009). The nurse as a health educator: Concepts, principles and strategies. Philippines: Educational Publishing House.

Tomey, AM \& Alligood, MR. (2002) Nursing theorists and their work. $5^{\text {th }}$ edition. Singapore: Mosby Inc. 